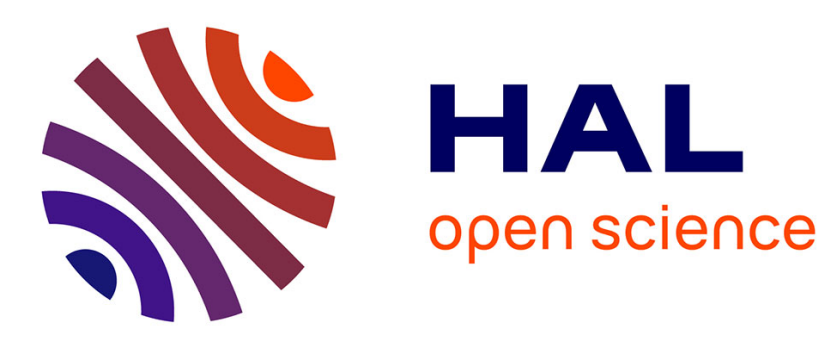

\title{
French vascular physicians' practices in indicating antiplatelet and anticoagulation therapy in venous thromboembolism
}

Antoine Fayol, Damien Lanéelle, Clément Hoffmann, Guillaume Mahé, Isabelle Mahé

\section{To cite this version:}

Antoine Fayol, Damien Lanéelle, Clément Hoffmann, Guillaume Mahé, Isabelle Mahé. French vascular physicians' practices in indicating antiplatelet and anticoagulation therapy in venous thromboembolism. VASA, 2019, 48 (4), pp.355 - 360. 10.1024/0301-1526/a000789 . hal-03116533

\section{HAL Id: hal-03116533 \\ https://hal.science/hal-03116533}

Submitted on 26 Jan 2021

HAL is a multi-disciplinary open access archive for the deposit and dissemination of scientific research documents, whether they are published or not. The documents may come from teaching and research institutions in France or abroad, or from public or private research centers.
L'archive ouverte pluridisciplinaire HAL, est destinée au dépôt et à la diffusion de documents scientifiques de niveau recherche, publiés ou non, émanant des établissements d'enseignement et de recherche français ou étrangers, des laboratoires publics ou privés. 


\title{
French vascular physicians' practices in indicating antiplatelet and anticoagulation therapy in venous thromboembolism
}

\author{
Antoine Fayol ${ }^{1}$, Damien Lanéelle ${ }^{2}$, Clément Hoffmann³ ${ }^{3}$ Guillaume Mahé ${ }^{4}$, \\ and Isabelle Mahé ${ }^{1,5,6}$ \\ Service de Médecine Interne, Hôpital Louis Mourier (Colombes), Assistance Publique - Hôpitaux de Paris (APHP), \\ Université Paris 7, Paris, France \\ 2 Service de Médecine Vasculaire, CHU Caen-Normandie, Caen, France \\ ${ }^{3}$ Service de Médecine Vasculaire, CHU Brest, Brest, France \\ ${ }^{4}$ Unité de Médecine Vasculaire, CHU Rennes, Rennes, France \\ ${ }^{5}$ Inserm UMR_S1140, Innovations thérapeutiques en hémostase, Paris, France \\ ${ }^{6}$ F-Crin Innovte, Saint-Etienne, France
}

\begin{abstract}
Summary: Background: As antiplatelet therapy becomes widespread, physicians face the issue patients being treated with antiplatelet agents (APA) and anticoagulants for venous thromboembolism (VTE). Bleeding risk of this combination is increased 1.5-2.5-fold. The aim of this survey is to assess French vascular physician's management of this combination at the beginning of the treatment and at 6 months of treatment for VTE. Patients and methods: French vascular physicians were surveyed between September and December 2017, using 4 fictional scenarios regarding a VTE event diagnosed in a patient under antiplatelet therapy plus isolated questions in an online questionnaire, sent by the French Society of Vascular Medicine to its members. Out of 1812 physicians, 179 returned valid questionnaires: the response rate was 9.9\%. Results: Firstly 97.2\% of respondents acknowledged extra risk with this combination; and 63\% ceased antiplatelet therapy when initiating anticoagulants; while 36\% did not. Secondly, four strategies emerged: $31.4 \%$ ceased APA and prescribed full-dose anticoagulants at initiation and at 6 months; 32\% associated reduced-dose anticoagulation with APA at 6 months, regardless of what they decided at initiation; $16.5 \%$ prescribed isolated full-dose anticoagulants at initiation and reduced-dose at 6 months; lastly $11.2 \%$ associated full-dose anticoagulant with antiplatelet therapy at initiation and at 6 months. Conclusions: French vascular physicians adopted different strategies according to estimated risk/benefit ratio. Prospective randomized controlled trials should compare these strategies in order to make recommendations.
\end{abstract}

Keywords: antiplatelet therapy, anticoagulation, venous thromboembolism disease

\section{Introduction}

Venous thromboembolic disease (VTE) includes pulmonary embolism (PE) and deep venous thrombosis (DVT). In Europe, the annual incidence in 2015 was 104 to 183 per 100,000 person-years [1]. Between 300,000 and 600,000 subjects are affected each year in the USA, causing considerable morbidity and mortality [2]. In episodes of unprovoked proximal DVT or PE, at least 3 months of oral anticoagulation therapy is currently recommended, usually by vitamin K antagonist (VKA) or direct oral anticoagulants (DOAC) (Grade 1B), with extended treatment in case of low-to-moderate hemorrhage risk (Grade 2B) [3].
At the same time, the number of patients under antiplatelet agents (APA) is constantly increasing, due to numerous and frequent indications related to atherothrombosis [4]. One of the most prescribed drugs in 2013 in France was aspirin; between 2010 and 2013, it sales increased by $4.1 \%$ annually [5].

About $15 \%$ of patients are taking APA when full-dose anticoagulation therapy is introduced for VTE [6-8], with as many as $38 \%$ among the elderly [9]. The bleeding risk is increased 1.5-2.5-fold by such combination in any indications [6-8]. Recommendations on APA management have been made for patients under anticoagulant therapy for atrial fibrillation $(\mathrm{AF})$ or peripheral artery disease. In case 
of stable coronary artery disease, DOAC should be continued alone if a compelling indication exists [10-12].

However, in patients under anticoagulants for VTE, data are sparse regarding management of concomitant antiplatelet therapy and especially regarding hemorrhage risk.

Given the scarcity of data, we conducted a French national survey of vascular physicians, to shed light on [1] their management of antiplatelet therapy (aspirin or clopidogrel) on diagnosing VTE requiring anticoagulation in the acute phase; and [2] management of anticoagulant and antiplatelet therapy 6 months into the anticoagulation therapy. The objective was to assess the practitioner's management of the treatment of a patient with an indication of APA and anticoagulant.

\section{Patients and methods}

\section{Questionnaire}

A questionnaire was drawn up and hosted on Google Forms. It is comprised of 3 parts: physician demographics, 4 clinical situations with 3 questions on procedure, and some isolated questions.

The fictional situation was designed to be common, with a clear indication for both long term anticoagulation therapy (recent diagnosis of unprovoked DVT or proven $\mathrm{PE}$ ) and antiplatelet therapy (proven coronary artery disease without coronary or peripheral stenting).

At diagnosis of VTE, the patient was receiving antiplatelet treatment by aspirin $75 \mathrm{mg}$ for stable coronaropathy 2 years after a myocardial infarction. Four clinical situations are distinguished, depending on the type of VTE and the type of anticoagulant (VKA or DOAC): unprovoked DVT treated by VKA (situation 1) or DOAC (situation 2), and unprovoked PE treated by VKA (situation 3) or DOAC (situation 4). The patient had similar age, characteristics and comorbidities to those included in phase III clinical trials for DOACs, without hemorrhagic risk factors, as a way to focus the practitioner on the treatment association regardless of the characteristics of the patients.

In each fictional situation, the practitioner was asked to detail APA management at the beginning of treatment and at 6 months into well-conducted anticoagulation therapy. At 6 months, the practitioner could choose to continue anticoagulation at full or at reduced dose, by VKA or DOAC, in line with guidelines.

We didn't include situations with an anticoagulation interruption at 6 months after initiation for a VTE treatment, as the issue of the combination anticoagulant/aspirin no longer arose Some isolated questions were added to the survey, to assess the physicians' knowledge and perception of each anticoagulant: risk of major hemorrhage, of recurrence of thromboembolism and possible risk of associating anticoagulants with APA.

The questionnaire was tested several times on several physicians, to assess understanding of items and selfadministration time. Participation was unpaid, and was anonymized. The full questionnaire is shown as electronic supplementary material (ESM).

The final version of the questionnaire was sent out by e-mail by the French Society of Vascular Medicine (SFMV) to its members, for online filling. French data protection commission (CNIL) approval was obtained $\left(\mathrm{n}^{\circ} 2150846 \mathrm{v}\right.$ 0). Review board approval was not required, as the study involved fictional situations and was not performed on humans. Between September 2017 and December 2017, 2 e-mail reminders were sent to all SFMV members $(n=1812)$. Data were entered on an Excel spreadsheet for analysis.

\section{Statistical analysis}

Mean values were calculated for each variable and compared with a Chi -test. The significance threshold was set at $\mathrm{p}<0.05$. Statistics were performed with $\mathrm{R}$ program version 3.5.1 (2018-07-02).

\section{Results}

Of those 1812 members, 778 opened the newsletter including the online questionnaire link, and 187 of the 778 physicians responded. Five questionnaires were excluded because the respondent was not practicing in France, and 3 because the respondent had replied twice (identified by their identical email address origin); these 3 were contacted to find out which reply should be counted. Thus, there were 179 fully completed questionnaires, the participation rate was $9.9 \%$.

\section{Demographics}

Both Respondent and SFMV member's characteristics, are displayed in Table I. Most (55.9\%) had community practice, and $31.8 \%$ had both community and hospital practice.

\section{Clinical situations}

\section{Initial treatment}

Taking all 4 situations together, $63 \%$ of physicians ( $\mathrm{n}=113$ ) would stop APA, while $36 \%(n=64)$ would continue APA after initiating anticoagulation; this was independent of location (DVT vs. PE) and of primary anticoagulant (DOAC vs. VKA) in all 4 situations $(\mathrm{p}=0.71)$.

\section{Attitude at 6 months}

Figure 1 presents management of anticoagulant and APA treatments at 6 months.

In the DVT-VKA situation, 2 options were preferred: $26.8 \%$ of physicians $(n=48)$ would associate APA with reduced-dose DOAC, and 29.6\% $(n=53)$ would stop APA and continue isolated full-dose VKA.

In the DVT-DOAC situation, 3 options were adopted: most $(\mathrm{n}=73,40.8 \%)$ associated APA with reduced-dose 
Table I. Population characteristics.

\begin{tabular}{|c|c|c|c|}
\hline \multicolumn{3}{|c|}{ Population characteristics $(n=179)$} & \multirow{2}{*}{$\frac{\text { SFMV members }}{\text { Percentage (\%) }}$} \\
\hline & Number & Percentage (\%) & \\
\hline Male gender & 92 & 51.4 & 50.4 \\
\hline \multicolumn{4}{|l|}{ Age } \\
\hline Less than 30 years & 2 & 1.1 & 1 \\
\hline Between 31 and 40 years & 28 & 15.6 & 18 \\
\hline Between 41 and 50 years & 44 & 24.6 & 19 \\
\hline Between 51 and 60 years & 88 & 49.2 & 36 \\
\hline Between 61 and 70 years & 16 & 8.9 & 23 \\
\hline More than 70 years & 1 & 0.6 & 3 \\
\hline \multicolumn{4}{|l|}{ Type of practice } \\
\hline Community (Vascular MD) & 100 & 55.9 & 78.7 \\
\hline Community + Hospital (Vascular MD) & 57 & 31.8 & NA \\
\hline Hospital (Vascular MD) & 17 & 9.5 & 21.3 \\
\hline Cardiologist & 2 & 1.1 & NA \\
\hline Internal medicine & 3 & 1.7 & NA \\
\hline
\end{tabular}
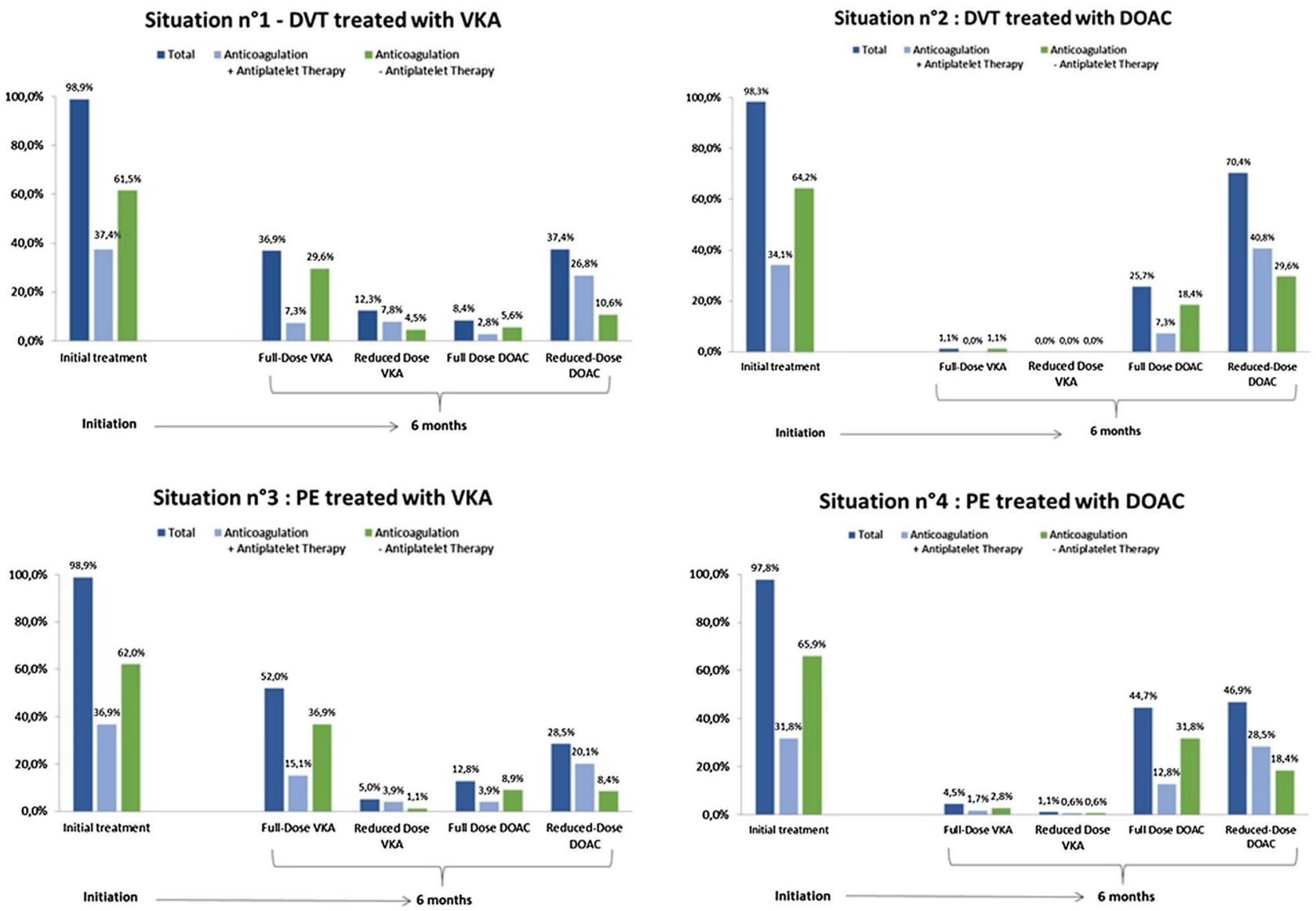

Figure 1. Management of antiplatelet and anticoagulation therapy in 4 clinical situations, at initiation (left) and at 6 months (right). (DVT: deep vein thrombosis; PE: pulmonary embolism; full-dose VKA: vitamin K agonist (INR target: between 2 and 3); DOAC: direct oral anticoagulant; reduceddose VKA: vitamin K agonist (INR target: between 1.5 and 2); reduced-dose DOAC: rivaroxaban $10 \mathrm{mg} /$ day or apixaban $2.5 \mathrm{mg} \times 2$ per day).

DOAC; $29.6 \%(\mathrm{n}=53)$ would stop APA and continue reduced-dose DOAC; $18.4 \%(\mathrm{n}=33)$ would stop APA and continue full-dose DOAC.

In the PE-VKA situation, results were similar to those for DVT-VKA, with 2 options preferred: most $(\mathrm{n}=66,36.9 \%)$ would stop APA and continue full-dose VKA; 20.1\% $(\mathrm{n}=36)$ would associate APA with reduced-dose DOAC.

In the PE-DOAC situation, results were similar to those for DVT-DOAC, with 3 options at 6 months: $28.5 \%$ would associate APA with reduced-dose DOAC; $18.4 \%$ would stop 
APA and continue reduced-dose DOAC; and 31.8\% would stop APA and continue full-dose DOAC.

\section{Overall management}

As there were no significant differences in primary antiplatelet therapy according to location or molecule, attitudes at initiation of anticoagulation and at 6 months were grouped for analysis. The objective was to determine common strategies applied by vascular physicians:

- $11.2 \%$ of physicians would prescribe APA at the beginning of the treatment and at 6 months associated with full-dose anticoagulation.

- $31.4 \%$ would stop APA at the beginning of treatment and at 6 months, and prescribe full-dose anticoagulation.

- $16.5 \%$ would stop APA at the beginning of treatment and at 6 months, and prescribe initially full-dose anticoagulation, and reduced-dose at 6 months.

- $32.0 \%$ would prescribe APA associated with reduceddose anticoagulation at 6 months, following initial fulldose anticoagulation without (13.4\%) or associated with APA (18.6\%).

We further summarized the responses to the 2-specific anticoagulant at 6 months $(\mathrm{n}=358$ for DOAC and VKA), $29 \%(\mathrm{n}=104)$ would replace DOAC by VKA, while $45 \%$ $(\mathrm{n}=156)$ would replace VKA by DOAC.

\section{Responses to single questions}

\section{Frequency of association}

Overall, $85 \%(n=152)$ of respondents had been involved with initial prescription, or renewal prescription of APA and anticoagulant treatment, including $70 \%(\mathrm{n}=126)$ in the last 6 months.

\section{Assessment of hemorrhage risk}

Firstly $97.2 \%$ of respondents considered there was an extra risk of bleeding when antiplatelet therapy is associated with anticoagulant; and 170 (95\%) considered this to apply to both VKA and DOAC.

Secondly $82.7 \%$ of respondents considered that isolated VKA showed greater hemorrhage risk than isolated DOAC, 19 physicians $(\mathrm{n}=10.6 \%)$ considered the risk to be similar for both, and 11 considered that DOACs incurred no risk of hemorrhage.

\section{VTE recurrence risk}

Lastly, $83.2 \%$ of respondents considered VKA and DOAC to be equivalent in preventing recurrence; 24 physicians (13.4\%) thought DOAC more effective than VKA, and $1(0.6 \%)$ thought the opposite.

\section{Discussion}

The present survey was, to our knowledge, the first to focus on vascular physicians' management of antiplatelet therapy when treating patients with VTE. The first finding was that the situation is frequently encountered: $70 \%$ of respondents had faced it in the previous 6 months.

Most French vascular physicians (97.2\%) were aware of the extra risk associated with this combination of treatments in VTE. This can be explained by corresponding findings in clinical situations such as AF after myocardial infarction or peripheral artery disease [13]. The international guidelines on APA management are clear regarding AF or peripheral artery disease; they recommend to stop antiplatelet therapy in case of stable coronary disease, unlike VTE, for which there are no randomized studies and few references in the literature. The only available reports are for subgroups receiving APA at inclusion, not specifying whether treatment was continued thereafter [6-8].

At the initiation of the anticoagulation for VTE disease, approximately two third of respondents would cease the antiplatelet therapy. Our result is comparable with the findings in the RIETE registry (63\% in our study, $62 \%$ according to the RIETE registry, p-value $=0.92$ ) [7]. In this registry, $76 \%$ of patients who received antiplatelet therapy at the initiation of anticoagulation had a history of prior coronary artery disease, cerebral ischemia, or peripheral artery disease; and in half of the case VTE was unprovoked [7]. In our study, we decided to choose a similar patient, with a history of coronary artery disease and without hemorrhagic risk factor, to represent one of the most likely situations encountered in clinical practice, including an indisputable indication to APA.

However, the assessment of an individual's hemorrhagic risk should take into account all the patient characteristics, and should not be reduced to the simple evaluation of drug combination. Recently a review published in 2017, suggested stopping the antiplatelet therapy for any duration of anticoagulant treatment, unless there is an acute indication (such as a recent cardiac event) [14]. Authors previously warned about the necessity to evaluate the benefit of this combination and the optimum DOAC dose when combined with an APA.

Clinical scores or algorithms allowing an objective evaluation of the hemorrhage risk but only in specific and limited situations; such as the HAS-BLED used with AF patients, or VTE recurrence risk (HERDOO2) used in patients with VTE $[15,16]$. The lack of data also impacts the design of the hemorrhage risk scores related to anticoagulation in patients treated for VTE; some take into account an ongoing antiplatelet therapy [17], others do not [18].

In the absence of guidelines, the present survey provides interesting information on the treatment strategies currently used. Results for the four fictional situations revealed 4 strategies, considering the 3 major risks; the risk of recurrence of thromboembolism, bleeding risk associated with APA/anticoagulant combination, and cardiovascular risk.

Concerning the risk of recurrence of thromboembolism, Boutitie et al. showed that, in patients with unprovoked VTE, the risk was high in the weeks following the event, then decreasing with treatment prolonged for at least 
6 months; the benefit of anticoagulant therapy was not maintained after termination $[19,20]$. Before the publication of trials of DOACs for extended treatment of VTE, there were 2 options available at 6 months [21]: maintenance of full-dose VKA with target INR 2-3, or termination. VKA dose reduction, with INR 1.5-2, was less effective than continued full-dose therapy, in preventing recurrence. The advent of DOACs enabled new strategies: prolonging fulldose anticoagulation beyond 6 months, using a DOAC $[22,23]$, or reduced-dose DOAC anticoagulation. The latter demonstrated an efficacy comparable to that of full-dose anticoagulation in preventing recurrence of thromboembolism without increasing hemorrhage risk versus placebo $[24,25]$. Decision criteria between full and reduced dose anticoagulation for extended treatment of VTE remain to be defined.

The risk of major hemorrhage under anticoagulation treatment is stable over time [20]. The meta-analysis of clinical trials of DOACs in VTE by Blecker et al. found an odds-ratio of 0.59 (95\% CI 0.36-0.97) on favor of DOACs versus VKA [26]. In the present study, $45 \%$ of physicians switched to DOAC from initial VKA, reducing the risk of major hemorrhage.

Cardiovascular risk, on the other hand, increases over time and is related to comorbidity [27]. Some studies reported similar preventive effects between oral anticoagulation and antiplatelet therapy [28]. Andreotti et al. concluded that aspirin associated with VKA (target INR, 2-3) following myocardial infarction doubled the risk of major hemorrhage, without effectively preventing major cardiovascular events [13].

Knowledge of these three risks combined with the relative importance attached to each influence's treatment strategy. Four strategies emerged from the present findings.

We can hypothesize for one-third of practitioners who definitely stopped APA, that full-dose anticoagulant prevents both risk of thromboembolic recurrence and cardiovascular risk. This strategy is actually suggested in the literature [14].

Another third of practitioners associated APA with reduced-dose anticoagulation at 6 months. It can suggest that the decreased risk of VTE recurrence at 6 months allows the anticoagulation dose to be lowered; while cardiovascular risk remains insufficiently prevented, justifying the keeping of APA. On the contrary, some physicians considered that cardiovascular risk is sufficiently prevented by reduced-dose anticoagulation and did not justify the reintroduction of APA.

Lastly, some physicians associated APA with anticoagulant therapy. Even if there is an increased risk of bleeding in this combination, some physicians probably think that anticoagulation alone is not as effective as this combination for covering both thromboembolic and cardiovascular risks.

Physicians facing the question of antiplatelet therapy associated with anticoagulant therapy for patients presenting both indications show contrasting attitudes, reflecting contrasting assessment of the afore-mentioned risks according to the individual patient. These contrasting attitudes lightened the difficulty to answer this question for physician, and the need of prospective clinical trials to clarify this question.

\section{Limitations}

The first limitation of this study lies in its design: a survey of practices based on fictional scenarios. However, the situations presented were representative of those encountered in clinical practice.

Second, the survey was based on a forced-choice MCQ. Some respondents may have chosen one proposal by default or might have wished to suggest another. However, the questionnaire offered responses in line with current treatment trends in VTE, allowing the largest possible number of associations.

Last, the response rate was 9.9\%. Despite the support of the French Society of Vascular Medicine (SFMV); the respondents may have been more involved in treating VTE and thus more interested in the issue than the non-respondents.

\section{Conclusions}

French vascular physicians are aware of the extra risk of bleeding when antiplatelet therapy is associated with anticoagulation therapy in VTE.

Four treatment strategies are used to manage antiplatelet therapy at initiation of anticoagulation and at 6 months, depending on the respective importance the physician assigns to cardiovascular risk, risk of recurrence of thromboembolism, and major hemorrhage risk.

The present lack of data requires prospective randomized trials to compare strategies and draw up clear guidelines for physicians to improve patient management.

\section{Electronic supplementary material}

The electronic supplementary material (ESM) is available with the online version of the article at https://doi.org/ 10.1024/0301-1526/a000789.

ESM 1. Questionnaire.

The questionnaire by the French Society of Vascular Medicine.

\section{References}

1. Heit JA. Epidemiology of venous thromboembolism. Nat Rev Cardiol. 2015;12(8):464-74

2. Beckman MG, Hooper, WC, Critchley, SE, Ortel, TL. Venous Thromboembolism. Am J Prev Med. 2010;38(4):S495-501.

3. Kearon C, Akl EA, Ornelas J, Blaivas A, Jimenez D, Bounameaux H, et al. Antithrombotic Therapy for VTE Disease. Chest. 2016;149(2):315-52. 
4. Elwood P, Morgan G, Brown G, Pickering J Aspirin for everyone older than 50? BMJ. 2005;330(7505):1440-1.

5. Agence Nationale de Securite du Medicament (ANSM) . Analyse des ventes de medicaments en France en 2013. 2018. Available from: http://ansm.sante.fr/var/ansm_site/storage/original/ application/3df7b99f8f4c9ee634a6a9b094624341.pdf

6. Majeed A, Goldhaber SZ, Kakkar A, Kearon C, Eriksson H, Kreuzer J, et al. Bleeding events with dabigatran or warfarin in patients with venous thromboembolism. Thromb Haemost. 2016;115(02):291-8.

7. Tzoran I, Brenner B, Sakharov G, Trujillo-Santos J, Lorenzo A, Madridano O, et al. Clinical outcome in patients with venous thromboembolism receiving concomitant anticoagulant and antiplatelet therapy. Eur $J$ Intern Med. 2014;25(9):821-5.

8. Nisio MD, Raskob G, Büller HR, Grosso MA, Zhang G, Winters $S M$, Prediction of major and clinically relevant bleeding in patients with VTE treated with edoxaban or vitamin $\mathrm{K}$ antagonists. Thromb Haemost. 2017;117(4):784-93.

9. Scherz N, Méan M, Limacher A, Righini M, Jaeger K, Beer H-J, Prospective, multicenter validation of prediction scores for major bleeding in elderly patients with venous thromboembolism. J Thromb Haemost. 2013;11(3):435-43.

10. Kirchhof P, Benussi S, Kotecha D, Ahlsson A, Atar D, Casadei B, 2016 ESC Guidelines for the management of atrial fibrillation developed in collaboration with EACTS. Eur Heart J. 2016;37(38):2893-962.

11. Macle L, Cairns J, Leblanc K, Tsang T, Skanes A, Cox JL, et al. 2016 Focused Update of the Canadian Cardiovascular Society Guidelines for the Management of Atrial Fibrillation. Can J Cardiol. 2016;32(10):1170-85.

12. Aboyans V, Ricco J-B, Bartelink M-LEL, Björck M, Brodmann M, Cohnert T, et al. 2017 ESC Guidelines on the Diagnosis and Treatment of Peripheral Arterial Diseases, in collaboration with the European Society for Vascular Surgery (ESVS). Eur Heart J. 2018;39(9):763-816.

13. Andreotti F, Testa L, Biondi-Zoccai GGL, Crea F. Aspirin plus warfarin compared to aspirin alone after acute coronary syndromes: an updated and comprehensive meta-analysis of 25307 patients. Eur Heart J. 2006;27(5):519-26.

14. Floyd CN, Ferro A. Indications for anticoagulant and antiplatelet combined therapy. BMJ. 2017;359:j3782.

15. Poli D, Palareti G. Assessing recurrence risk following acute venous thromboembolism: use of algorithms. Curr Opin Pulm Med. 2013;19(5):407-12.

16. Nieto JA, Solano R, Trapero Iglesias N, Ruiz-Giménez N, Fernández-Capitán C, Valero B, et al. Validation of a score for predicting fatal bleeding in patients receiving anticoagulation for venous thromboembolism. Thromb Res. 2013; 132(2): 175-9.

17. Seiler E, Limacher A, Mean M, Beer H-J, Osterwalder J, Frauchiger B, et al. Derivation and validation of a novel bleeding risk score for elderly patients with venous thromboembolism on extended anticoagulation. Thromb Haemost. 2017; 117(10).

18. Klok FA, Hösel V, Clemens A, Yollo WD, Tilke C, Schulman S, et al. Prediction of bleeding events in patients with venous thromboembolism on stable anticoagulation treatment. Eur Respir J. 2016;48(5):1369-76.

19. Boutitie F, Pinede L, Schulman S, Agnelli G, Raskob G, Julian J, et al. Influence of preceding length of anticoagulant treatment and initial presentation of venous thromboembolism on risk of recurrence after stopping treatment: analysis of individual participants' data from seven trials. BMJ. 2011 May 24;342.

20. Couturaud F, Sanchez O, Pernod G, Mismetti P, Jego P, Duhamel E, et al. Six Months vs Extended Oral Anticoagulation After a First Episode of Pulmonary Embolism: The PADISPE Randomized Clinical Trial. JAMA. 2015;314(1):31.

21. Kearon C, Ginsberg JS, Kovacs MJ, Anderson DR, Wells P, Julian JA, et al. Comparison of Low-Intensity Warfarin Therapy with Conventional-Intensity Warfarin Therapy for Long-Term Prevention of Recurrent Venous Thromboembolism. N Engl J Med. 2003;349(7):631-9.

22. Agnelli G, Buller HR, Cohen A, Curto M, Gallus AS, Johnson M, et al. Apixaban for Extended Treatment of Venous Thromboembolism. N Engl J Med. 2013;368(8):699-708.

23. Oral Rivaroxaban for Symptomatic Venous Thromboembolism. N Engl J Med. 2010;363(26):2499-510.

24. Weitz JI, Lensing AWA, Prins MH, Bauersachs R, BeyerWestendorf J, Bounameaux H, et al. Rivaroxaban or Aspirin for Extended Treatment of Venous Thromboembolism. N Engl J Med. 2017;376(13):1211-22.

25. Vasanthamohan L, Boonyawat K, Chai-Adisakopha C, Crowther M. Reduced dose direct oral anticoagulants in the extended treatment of venous thromboembolism: a systematic review and meta-analysis. J Thromb Haemost. 2018.

26. Bleker S, Brekelmans M, Eerenberg E, Cohen A, Middeldorp S, Raskob G, et al. Clinical impact of major bleeding in patients with venous thromboembolism treated with factor $X$ a inhibitors or vitamin $\mathrm{K}$ antagonists: An individual patient data metaanalysis. Thromb Haemost. 2017;117(10):1944-51.

27. Piepoli MF, Hoes AW, Agewall S, Albus C, Brotons C, Catapano AL, et al. 2016 European Guidelines on cardiovascular disease prevention in clinical practice: The Sixth Joint Task Force of the European Society of Cardiology and Other Societies on Cardiovascular Disease Prevention in Clinical Practice (constituted by representatives of 10 societies and by invited experts)Developed with the special contribution of the European Association for Cardiovascular Prevention \& Rehabilitation (EACPR). Eur Heart J. 2016;37(29):2315-81.

28. Cairns J. Oral anticoagulants or aspirin after myocardial infarction? The Lancet. 1994;343(8896):497-8.

\section{History}

Submitted: 14.12 .2018

Accepted after revision: 05.03.2019

Published online: 04.04.2019

\section{Conflicts of interests}

No conflicts of interest exist.

\section{Correspondence address}

Isabelle Mahé, MD, PhD

178, Rue des Renouillers 92701 Colombes cedex

France

isabelle.mahe@aphp.fr 